3 Palmer, K. N. V., et al., Lancet, 1969, 2, 1092

4 Leary, W. P., Coleman, A. J., and Asmal, A. C., South African Medical fournal, 1973, 47, 1245 .

5 Bianco, S., et al., British fournal of Diseases of the Chest, 1972, 66, 27.

6 Snashall, P. D., and Boother, F. A., Bulletin de Physiopathologie Respiratoire, $1972,8,503$.

${ }^{7}$ Bianco, S., et al., British Medical fournal, 1974, 4, 18.

${ }^{8}$ Kerr, J. W., Govindaraj, M., and Patel, K. R., British Medical fournal $1970,2,139$.

${ }^{9}$ Gaddie, J., et al., British fournal of Diseases of the Chest, 1972, 66, 141.

10 Collier, J. G., et al., British fournal of Pharmacology, 1972, 44, 286.
11 Farmer, J. B., et al., British fournal of Pharmacology, 1972, 45, 660.

12 Palmer, K. N. V., and Diament, M. L., Lancet, 1969, 1, 591.

13 Richards, D. A., personal communication, 1973.

4 Kumana, C. R., Marlin, G. E., and Smith, D. M., in Proceedings of British Pharmacological Society. In press.

15 Richards, D. A., et al., British fournal of Clinical Pharmacology. In Press.

16 Boakes, A. J., Knight, E. J., and Prichard, B. N. C., Clinical Science, 1971, 40, $18 \mathrm{P}$.

17 Kennedy, I., and Levy, G. P., in Proceedings of Australian Physiological and Pharmacological Society. In press.

18 Taylor, S. H., British Medical fournal, 1974, 19, 49.

\title{
Fibrinolytic Capacity of Arm and Leg Veins after Femoral Shaft Fracture and Acute Myocardial Infarction
}

\author{
J. M. RAWLES, CHARLES WARLOW，D. OGSTON
}

British Medical fournal, 1975, 2, 61-62

\section{Summary}

The local fibrinolytic activity generated in the leg and arm veins during venous occlusion (fibrinolytic capacity) and the systemic fibrinolytic activity were measured at intervals in 11 patients after fracture of the femoral shaft and in 11 patients after acute myocardial infarction. In both groups the fibrinolytic capacity of the leg .veins and the systemic fibrinolytic activity were significantly reduced two days after the onset of tissue injury. The fibrinolytic capacity of the arm veins was not altered. These results provide a possible explanation for the predilection of venous thrombosis for the leg veins after accidental trauma and acute myocardial infarction.

\section{Introduction}

Deep venous thrombosis of the legs is a common complication of many forms of acute tissue injury-for example, surgery, ${ }^{1}$ accidental trauma, ${ }^{2}$ acute myocardial infarction, ${ }^{3}$ and strokes. ${ }^{4}$ Under these circumstances changes in platelet number and function, coagulation, and fibrinolysis occur which might favour thrombosis. ${ }^{5}$ Venous thrombosis more often affects the leg veins than the arm veins, ${ }^{6}$ however, which suggests that there is some difference in predisposition to thrombosis between the upper and lower limbs. The leg vein wall has a lower plasminogen activator content than the arm vein wall, ${ }^{7}$ and the release of plasminogen activator in response to venous occlusion"fibrinolytic capacity" - is also considerably less in the legs than in the arms. ${ }^{7}$ We studied the sequential changes in the fibrinolytic capacity of the arm and leg veins and the systemic fibrinolytic activity in patients who had fractured their femoral shaft or suffered acute myocardial infarction.

\section{Patients and Methods}

Ten men and one woman (age 18-71 years) were studied after fracture of one femoral shaft without other significant injury. They were treated by traction for at least two months. Blood samples were obtained two and 10 days after injury and again two months later. Seven patients were also studied two or more months after mobilization,

Department of Medicine, Aberdeen University, Aberdeen AB9 2ZD J. M. RAWLES, M.B., M.R.C.P., Senior Registrar (Present address: West Cornwall Hospital, Penzance)

CHARLES WARLOW, M.B., M.R.C.P., Lecturer (Present address: National Hospital for Nervous Diseases, Queen Square, London)

D. OGSTON, M.D., F.R.C.P., Senior Lecturer when they were ambulant for most of the day. Another 11 men (age 41-63) were studied two and 10 days after the clinical onset of acute myocardial infarction confirmed by serial electrocardiograms and raised serum aspartate aminotransferase levels.

In all patients blood was first drawn from an antecubital vein without venous occlusion for measurement of the systemic fibrinolytic activity. Sphygmomanometer cuffs were then applied to the upper arm (cuff size $22 \times 12 \mathrm{~cm}$ ) and thigh (cuff size $50 \times 17 \mathrm{~cm}$ ). The uninjured leg was used in the patients with fractures. The cuffs were simultaneously inflated to mid-way between the systolic and diastolic arterial blood pressure as recorded in the arm for 12.5 minutes. Blood was then withdrawn from a vein on the dorsum of the foot and from an antecubital vein before release of the occluding cuffs. The fibrinolytic activity of these samples obtained after venous occlusion was taken as the "fibrinolytic capacity." The fibrinolytic activity of each blood sample was measured by the euglobulin clot lysis time method, ${ }^{\circ}$ using a clot lysis time recorder (Carmanan Instrumentation Ltd., Glasgow). The results were expressed by plotting the lysis times logarithmically against units of fibrinolytic activity, ${ }^{10} 10$ units being arbitrarily equated with a lysis time of 50 minutes. The paired $t$ test was used for statistical comparisons.

\section{Results}

In both groups of patients the fibrinolytic capacity of the leg veins and the systemic fibrinolytic activity were significantly reduced two days after the onset of tissue injury. There was a significant increase $(\mathbf{P}<0.01)$ in the mean fibrinolytic activity of systemic blood between the second and 10th day after tissue injury in both groups (see table). In the patients with fractured femurs there was no further significant change two months after injury, though in the seven patients studied after mobilization there was a small but significant rise $(P<0.05)$ in systemic fibrinolytic activity from the level at two months. There were no significant changes in the mean arm fibrinolytic capacity after fracture or myocarcial infarction. There was, however, a significant increase in the mean leg fibrinolytic capacity of the leg veins between two and 10 days after fracture of the femur $(P<0.001)$ and acute myocardial infarction $(P<0.01)$. There was no further significant change either two months after femoral fracture or after mobilization in the seven patients who were studied when ambulant.

There was high correlation between the individual values of systemic fibrinolytic activity and leg fibrinolytic capacity $(r=0.79 ; P<0.001)$, but the correlation between systemic activity and arm fibrinolytic capacity was less close $(r=0.31 ; P<0.05)$.

\section{Discussion}

Our findings support observations of the early depression of systemic fibrinolytic activity after accidental trauma ${ }^{11}$ and acute myocardial infarction. ${ }^{12}$ We also found a significant depression in the fibrinolytic capacity of the legs only two days after femoral shaft fracture or myocardial infarction which correlated with the changes in systemic fibrinolytic activity. If the generation of fibrinolytic activity in the venous system in response to venous 
Fibrinolytic Activity and Capacity after Fracture of Femoral Shaft and Myocardial Infarction

\begin{tabular}{|c|c|c|c|c|c|c|}
\hline & \multicolumn{6}{|c|}{ Mean Euglobulin Clot Lysis Time ( \pm S.E.) (Units) } \\
\hline & \multicolumn{4}{|c|}{ After Fracture } & \multicolumn{2}{|c|}{ After Infarction } \\
\hline & 2 Days & 10 Days & 2 Months & When Ambulant & 2 Days & 10 Days \\
\hline $\begin{array}{l}\text { Systemic fibrinolytic activity } \\
\text { Arm fibrinolytic capacity } \\
\text { Leg fibrinolytic capacity }\end{array}$ & $\begin{aligned} 1 \cdot 6 & \pm 0 \cdot 3 \\
14 \cdot 2 & \pm 2 \cdot 6 \\
3 \cdot 2 & \pm 0 \cdot 6\end{aligned}$ & $\begin{array}{r}3.0 \pm 0.4 \\
12.5 \pm 1.9 \\
8.0 \pm 1.0\end{array}$ & $\begin{array}{r}3.3 \pm 0.5 \\
14 \cdot 3 \pm 2.2 \\
9 \cdot 1 \pm 1.5\end{array}$ & $\begin{array}{r}4 \cdot 7 \pm 0 \cdot 6 \\
17 \cdot 5 \pm 2 \cdot 3 \\
8 \cdot 6 \pm 2 \cdot 0\end{array}$ & $\begin{aligned} 1 \cdot 7 & \pm 0 \cdot 4 \\
16 \cdot 8 & \pm 2 \cdot 9 \\
3 \cdot 1 & \pm 0 \cdot 7\end{aligned}$ & $\begin{aligned} & 2.9 \pm 0.4 \\
& 13.9 \pm 2.5 \\
& 5.6 \pm 0.7\end{aligned}$ \\
\hline
\end{tabular}

occlusion is due to the release of plasminogen activator from the vein wall ${ }^{13}$ our findings may be explained in two ways: there may be a decrease in the leg vein wall activator early after tissue injury, or the release of activator from the wall may be impaired. Whatever the mechanism, however, the difference between the changes in the fibrinolytic capacities of the arm and leg may be one explanation for the relative frequency of venous thrombosis in the legs compared with the arms after fracture of the femoral shaft and myocardial infarction. The early depression of leg fibrinolytic capacity may also be relevant to the observation that deep venous thrombosis usually starts at the time of or very soon after tissue injury. ${ }^{134}$

Our findings conflict with those of Karaca and Nilsson, ${ }^{14}$ who reported that the fibrinolytic capacity of the legs, in contrast to that of the arms, was increased after prolonged recumbency. One explanation for the differing conclusions is that these investigators studied different groups of individuals whereas we examined the same people sequentially.

The origin of the plasminogen activator responsible for the fibrinolytic activity of systemic blood is unknown. The close correlation between the fibrinolytic capacity of the legs and the systemic fibrinolytic activity suggests, however, that the leg veins are one important source of circulating plasminogen activator.
We thank the orthopaedic surgeons and physicians of the Aberdeen Royal Infirmary for allowing us to study patients under their care and the technicians in the department of medicine for undertaking the euglobulin clot lysis time assays.

\section{References}

${ }^{1}$ Kakkar, V. V., et al., American fournal of Surgery, 1970, 120, 527.

2 Sevitt, S., and Gallagher, N. G., British fournal of Surgery, 1960/1961, 48,475 .

3 Maurer, B. J., Wray R., and Shillingford, J. P., Lancet, 1971, 2, 1385.

4 Warlow, C. P., Ogston, D., and Douglas, A. S., Lancet, 1972, 1, 1305.

${ }^{5}$ Rawles, J. M., Ogston, D., and Douglas, A. S., Clinics in Haematology, 1973, 2, 79.

${ }^{6}$ Hume, M., Sevitt, S., and Thomas, D. P., Venous Thrombosis and Pulmonary Embolism. Cambridge, Harvard University Press, 1970.

? Pandolfi, M., et al., Lancet, 1967, 2, 127.

8 Robertson, B., Pandolfi, M., and Nilsson, I. M., Acta Chirurgica Scandinavica, 1972, 138, 429 .

' Nilsson, I. M., and Olow, B., Acta Chirurgica Scandinavica, 1962, 123, 247.

10 Sherry, S., et al., Fournal of Clinical Investigation, 1959, 38, 810.

${ }_{11}$ Innes, D., and Sevitt, S., fournal of Clinical Pathology, 1964, 17, 1.

12 Bennett, N. B., Ogston, C. M., and Ogston, D., Clinical Science, 1967, $32,27$.

${ }^{13}$ Chakrabarti, R., Birks, P. M., and Fearnley, G. R., Lancet, 1963, 1, 1288.

14 Karaca, M., and Nilsson, I. M., Acta Medica Scandinavica, 1971, 189, 325.

\title{
Doppler Ultrasound and Fetal Activity
}

\author{
HEDDWYN DAVID, JUDITH B. WEAVER, JAMES F. PEARSON
}

British Medical fournal, 1975, 2, 62-64

\section{Summary}

The possibility that Doppler ultrasound, as used in routine fetal monitoring by external cardiotocography, might stimulate fetal activity was investigated. A mean increase in fetal activity of over $90 \%$ was found, as judged by the fetal movement count.

\section{Introduction}

Some patients undergoing antenatal external cardiotocography with Doppler ultrasound reported an increase in fetal activity during monitoring. We investigated whether this response was consistent and whether ultrasound was the likely stimulating agent.

\footnotetext{
University Department of Obstetrics and Gynaecology, Welsh National School of Medicine, Cardifi CF4 4XN HEDDWYN DAVID, B.SC., M.B., Research Fellow JUDITH B. WEAVER, F.R.C.S., M.R.C.O.G., Lecturer JAMES F. PEARSON, M.D., M.R.C.O.G., Senior Lecturer and Consultant
}

\section{Patients and Methods}

Patients between 28 and 40 weeks of gestation were selected at random from inpatients used to counting fetal movements. The investigation was conducted in three parts-(1) assessment of fetal response to external cardiotocography using Doppler ultrasound with two different instruments to see whether it was due to an instrumental peculiarity; (2) a "sham" study to confirm objectivity; and (3) evaluation of the possibility that electrical currents from the apparatus stimulated fetal activity. This was achieved by occluding the transmission of ultrasound while retaining electrical contact.

In the first part of the study the Sonicaid FM2 and HewlettPackard 8025B cardiotocographs were used. Each has two abdominal inputs. One, the "tocograph head," detects the fetal heart beat using continuous Doppler ultrasound. The Sonicaid FM2 "ultrasonic head" consists of one transmitter and six peripheral ceramic receiving crystals; the Hewlett-Packard incorporates one transmitter and one receiving crystal. The ultrasonic energy output of the Sonicaid machine is about $12 \mathrm{~mW} / \mathrm{cm}^{2}$ of transducer head, and that of the Hewlett-Packard about $16 \mathrm{~mW} / \mathrm{cm}^{2}$ (manufacturers' data). In the second and third parts of the study only the Sonicaid FM2 was used.

Part 1-Fifteen patients were studied, eight with the Sonicaid FM2 and seven with the Hewlett-Packard 8025B. All rested before the investigation and were lying supine. The tocograph head was placed on the abdomen in the midline over the uterine fundus. The ultrasonic head was smeared with Aquasonic $100 \mathrm{gel}$ and placed where the fetal heart was most clearly heard. Both heads of the monitor were held in position by Tubigrip bandage. Each patient was studied for 30 minutes. During the first 15 minutes uterine activity alone was recorded, and then, unknown to the patient, the ultrasonic head was 